University of Nebraska - Lincoln

DigitalCommons@University of Nebraska - Lincoln

\title{
Longitudinal Associations Between Executive Control and Developing Mathematical Competence in Preschool Boys and Girls
}

\author{
Caron A. C. Clark \\ University of Oregon, caron.clark@unl.edu \\ Tiffany Sheffield \\ University of Nebraska-Lincoln, tsheffield2@unl.edu \\ Sandra A. Wiebe \\ University of Alberta, sandra.wiebe@ualberta.ca \\ Kimberly A. Espy \\ University of Nebraska-Lincoln, kespy2@unl.edu
}

Follow this and additional works at: https://digitalcommons.unl.edu/dcnlfacpub

Clark, Caron A. C.; Sheffield, Tiffany; Wiebe, Sandra A.; and Espy, Kimberly A., "Longitudinal Associations Between Executive Control and Developing Mathematical Competence in Preschool Boys and Girls" (2012). Developmental Cognitive Neuroscience Laboratory - Faculty and Staff Publications. 50. https://digitalcommons.unl.edu/dcnlfacpub/50

This Article is brought to you for free and open access by the Developmental Cognitive Neuroscience Laboratory at DigitalCommons@University of Nebraska - Lincoln. It has been accepted for inclusion in Developmental Cognitive Neuroscience Laboratory - Faculty and Staff Publications by an authorized administrator of DigitalCommons@University of Nebraska - Lincoln. 
Published in Child Development 84 (2012); doi: 10.1111/j.1467-8624.2012.01854.x

Copyright (C) 2012 Caron A. C. Clark, Tiffany D. Sheffield, Sandra A. Wiebe, and Kimberly A. Espy. Child Development is published by Society for Research in Child Development, Inc., and John Wiley \& Sons. Used by permission.

Published online September 24, 2012.

This work was supported by National Institutes of Health (NIH) Grants MH065668 and DA014661 to Kimberly Andrews Espy, Grant DA024769 to Sandra Wiebe, and Grant DA023653 to Kimberly Andrews Espy and Lauren Wakschlag. We thank members of the Developmental Cognitive Neuroscience Laboratory for assistance with data collection and coding, as well as the children and families who kindly participated in the research.

\title{
Longitudinal Associations Between Executive Control and
} Developing Mathematical Competence in Preschool Boys and Girls

\author{
Caron A. C. Clark, ${ }^{1,2}$ Tiffany D. Sheffield, ${ }^{2}$ Sandra A. Wiebe, ${ }^{3}$ and Kimberly A. Espy ${ }^{1,2}$ \\ 1. University of Oregon, 2. University of Nebraska-Lincoln, 3. University of Alberta \\ Corresponding author - Caron A. C. Clark, Department of Psychology, Straub Hall, 1227 \\ University of Oregon, Eugene, OR 97403; email carrie4@uoregon.edu
}

\begin{abstract}
Executive control (EC) is related to mathematics performance in middle childhood. However, little is known regarding how EC and informal numeracy differentially support mathematics skill acquisition in preschoolers. A sample of preschoolers (115 girls, 113 boys), stratified by social risk, completed an EC task battery at 3 years, informal numeracy assessments at 3.75 and 4.5 years, and a broad mathematics assessment during kindergarten. Strong associations were observed between latent EC at age 3 and mathematics achievement in kindergarten, which remained robust after accounting for earlier informal numeracy, socioeconomic status, language and processing speed. Relations between EC and mathematics achievement were stronger in girls than in boys. Findings highlight the unique role of EC in predicting which children may have difficulty transitioning to formal mathematics instruction.
\end{abstract}

Recent educational policies focused on accountability and high stakes testing have served to highlight significant achievement discrepancies for the most disadvantaged children in our society (Pigott \& Israel, 2005). Discrepancies are evident as early as school entry and have ongoing implications for educational success, employment, and quality of life (Denton \& West, 2002; Spreen, 1988). Internationally representative studies have revealed high intra-individual stability in academic performance, with $25 \%$ $35 \%$ of the variance in later achievement being accounted for by cognitive and academic skills at school entry (La Paro \& Pianta, 2000). Mathematics skills are a particularly strong predictor of later educational achievement: A recent meta-analysis showed that the relation between measures of mathematics taken at school entry and academic achievement in middle childhood and adolescence was twice as strong as that for early reading skills and 3 times as strong as that for early attention skills (Duncan et al., 2007). Studies also show that children who begin school with poor numeracy skills do not catch up with their peers. Instead, they show a depressed rate of growth in mathematics relative to their peers as academic demands grow increasingly rigorous and poor fluency in the basic skills limits the opportunity for new learning (Aunola, Leskinen, Lerkkanen, \& Nurmi, 2004). Given these sobering findings for school-aged children, attention has turned increasingly toward early childhood as a period when we might hope to enhance the skills necessary for successful transition to the classroom and divert the trajectory of progressive deficits in educational performance.

\section{Informal Mathematics}

By kindergarten age, children already have a large basis of informal knowledge in mathematics, defined as knowledge that is not taught in a formal schooling environment, but that is intuitive or built up through everyday experiences and informal teaching, including by parents and social partners (Resnick, 1989). In- 
formal numeracy appears to derive in part from a preverbal or "biologically primary" proclivity to attend to numeric information (Dehaene, 1997; Halberda, Mazzocco, \& Feigenson, 2008). Looking preference paradigms suggest that children as young as 6 months are able to identify magnitude changes for sets of fewer than three objects and to make approximate magnitude comparisons for larger numbers (Starkey, 1992; Wynn, 1995). However, an ability to deal with the abstract properties of number and to perform numeric manipulations is most apparent after children have gained verbal skills. For example, children are able to nominate the last item in a set as the sum of the set by the end of their 3rd year, suggesting that they have some understanding of the cardinal properties of number (Gelman \& Galistel, 1978). They begin to acquire words for the numbers 1-10 and to associate the symbolic number tags that they learn with exact magnitudes (Lipton \& Spelke, 2006). They acquire an understanding of part-whole relations and can make judgments about relative size (Krajewski \& Schneider, 2009; Levine, Jordan, \& Huttenlocher, 1992). From age 2.5 years, children progressively are able to solve nonverbal addition and subtraction problems (Huttenlocher, Jordan, \& Levine, 1994).

As children progress through early elementary school, their informal mathematics knowledge serves as a platform for the acquisition of formally taught mathematics (Gallistel \& Gelman, 1992; Huttenlocher et al., 1994). Children with less informal knowledge are at a disadvantage relative to their peers, as measures of early informal mathematics skills, including counting concepts, magnitude comparison, seriation, ordinal and cardinal understanding, predict mathematics achievement through middle childhood (Jordan, Glutting, \& Ramineni, 2010; Jordan, Kaplan, Ramineni, \& Locuniak, 2009). Correspondingly, children who meet criteria for mathematics learning disabilities (MLD) in middle childhood appear to struggle with basic numeric concepts, making more errors on counting tasks and showing lower performance on measures of magnitude comparison and number line approximation (Geary, Bailey, \& Hoard, 2009; Geary, Hoard, Byrd-Cracen, Nugent, \& Numtee, 2007).

Despite the importance of informal mathematics for later achievement, most of the instruments designed to measure mathematics understanding in preschoolers include simple counting or the assessment of numeric principles such as order irrelevance and one-to-one correspondence (Gersten, Jordan, \& Flojo, 2005; Jordan et al., 2010). These tests demand fairly sophisticated language skills if children are to demonstrate their counting knowledge effectively. Indeed, there is debate as to whether young children possess the mnemonic or comprehension abilities necessary for successful performance on these early mathematics tasks (Mix, Huttenlocher, \& Levine, 2002). Mathematics assessments may therefore lack sensitivity to individual differences at very young ages. Given these limitations, the assessment of broader precursors of academic learning may offer greater leverage for the early identification of children who are less prepared to transition to formal mathematics instruction.

\section{Executive Control (EC) in Preschool}

One example of these broader precursor skills for learning is EC, which can be defined as the system of cognitive processes that enable voluntary, flexible, and goal-directed behavior (Welsh, 2002). Although it is clear that performance on EC tasks improves rapidly during the preschool period (Garon, Bryson, \& Smith, 2008), there is currently debate regarding the fundamental structure of EC in these early years. In the adult literature, working memory, inhibitory control, and cognitive flexibility or set shifting typically are differentiated as constituent processes that fall under the rubric of EC (Miyake, Friedman, Emerson, Witzki, \& Howerter, 2000). Factor analytic analyses in middle childhood generally suggest a similar picture (e.g., Huizinga, Dolan, \& Molan, 2006). In contrast, the weight of the evidence for early childhood samples suggests that putative constituents of EC are less easily parsed. Sophisticated confirmatory factor analysis (CFA) studies encompassing different samples and varying tasks with theoretically different executive demands have indicated that EC measures administered in preschool are best captured empirically by a single executive construct (Wiebe, Espy, \& Charak, 2008; Wiebe et al., 2011; Willoughby, Blair, Wirth, \& Greenberg, 2010). This is in keeping with neuroimaging studies, which show that neural activity during EC tasks becomes more focal and confined to specific brain regions with age (Bell, Wolfe, \& Adkins, 2007; Durston et al., 2006). Based on these findings, it appears that EC processes in early childhood are not divisible into specific subcomponents, as has often been assumed in previous studies.

\section{EC and Mathematics}

There is substantial evidence for a developmental link between EC and mathematical competence, 
as manifest measures designed to capture individual differences in theoretical components of EC, including working memory, set shifting, and inhibitory control, typically correlate well with measures of mathematics achievement (Bull, Johnston, \& Roy, 1999; Mazzocco \& Kover, 2007; St Clair-Thompson \& Gathercole, 2006). For instance, Mazzocco and Kover (2007) showed that 6- to 7-year-old children with MLD were less likely to graduate to higher levels of a set-shifting task than children without MLD. In a typically developing sample, St Clair-Thompson and Gathercole (2006) found significant correlations between performance on measures of inhibition and working memory and national measures of mathematics achievement administered at age 11 years, although these associations were not specific to mathematics, incorporating English and science as well.

Until recently, most studies relating EC to mathematics achievement were cross-sectional and confined to older children. However, as Noel (2009) cogently argues, there is clear theoretical rationale for believing that EC might play a central role in the acquisition of early counting and mathematical concepts. For instance, counting involves holding sequential information in working memory and constantly updating this information while suppressing older information to do so. Similarly, appreciation of the principle that 4 is part of 5 but that 5 is also part of 6 , inherently draws upon cognitive flexibility or the ability to represent 5 from two different standpoints. Conceptually, then, informal mathematics skills and EC abilities in preschool children overlap because of the common demands in manipulating numeric information to demonstrate knowledge.

In support of the idea that EC is involved in early mathematics skill development, recent studies have suggested that early EC may be a precursor to, or a useful predictor of, mathematics achievement even at young ages (Bull, Espy, Wiebe, Sheffield, \& MizeNelson, 2011; Clark, Pritchard, \& Woodward, 2010; Kroesbergen, Van Luit, Lieshot, Van Loosbroek, \& Van de Rijt, 2009; Welsh, Nix, Blair, Bierman, \& Nelson, 2010). For instance, Bull, Espy, and Wiebe (2008) used growth curve modeling to examine the relations between EC in preschoolers with a mean age of 4.5 years and growth in mathematics and reading across the ensuing 3 years. Preschoolers with higher EC task scores showed higher performance on national mathematics achievement tests across the transition to formal schooling even after accounting for reading ability. Similarly, Clark et al. (2010) showed that a composite measure of EC at age 4 years was correctly able to classify $80 \%$ of children as average or low performing in mathematics by age 6 years.

Despite these findings, there remain several questions regarding the relation of early EC to later mathematics achievement. One important question pertains to the relative importance of early EC versus informal numeracy. In extant studies examining the EC-mathematics relation, the role of informal mathematics abilities generally has not been considered, with the measurement of mathematics often being limited to single scales from broad standardized measures. From a theoretical standpoint, the tasks used to measure early numeracy often resemble measures used to evaluate EC, in that children are asked to remember how many objects are behind a screen or count pictures of one object while ignoring another, for example. Therefore, much of the relation between EC and mathematics achievement reported in previous studies may be driven by similar task properties. "Subtracting out" the role of informal mathematics test scores in predicting later mathematics proficiency may provide a clearer understanding of the differential predictive validity of each construct. From an applied perspective, it is important to determine whether or not the assessment of early EC offers clinical utility above and beyond available numeracy measures so that assessment and educational intervention may be targeted appropriately. If EC does not offer any predictive utility beyond the assessment of informal mathematics, then preschool efforts are perhaps better focused on mathematics instruction rather than on executive skill building.

The first aim of this study was to disentangle the respective roles of early EC and children's informal mathematics knowledge in predicting mathematics proficiency at kindergarten entry age. Former studies generally have relied on manifest EC tasks, whose psychometric properties have not been characterized in preschool populations. To overcome this limitation, we employed CFA methods to capture empirically the distinct variance shared by multiple manifest EC measures, thereby gaining a purer representation of the relation between latent EC and mathematics performance. Unlike previous studies, we also examined EC skills at a young age, 3 years, to quantify better the early sensitivity of EC measures to later mathematics achievement.

\section{Sex Differences and Mathematics}

Another limitation of extant studies examining the relation between EC and mathematics is that there has been a lack of attention to sex differences 
in these relations. Although sex differences in mean performance on preschool mathematics assessments are seldom observed (Geary, 1994; Ponitz, RimmKaufman, Brock, \& Nathanson, 2009), it is possible that preschool girls and boys may draw differentially on early cognitive skill sets to support mathematics performance. For instance, elementary school studies show that girls and boys prefer different strategies when confronted with mathematics problems, girls preferring to use manipulatives and boys preferring to use rote retrieval or spatial strategies (Carr \& Jessup, 1997). To our knowledge, only two studies have examined sex differences in the relations between EC and mathematics achievement in preschool children. Matthews, Ponitz, and Morrison (2009) showed that although girls achieved higher mean scores on EC measures, boys and girls showed a comparable, positive association between EC performance (measured with a single task) and mathematics performance a year later. Because this study utilized only a single measure of $\mathrm{EC}$, it was not possible to examine whether underlying constructs were captured similarly in boys and girls. In a cross-sectional study that did incorporate a latent variable framework with multiple executive measures, Bull et al. (2011) found that there were no significant differences in relations between EC and mathematics across the genders, but that the relation between language abilities and concurrent mathematics achievement was stronger in boys than that in girls. These cross-sectional findings have yet to be replicated with a longitudinal design. Therefore, the second aim of the study was to determine whether or not developmental pathways between early EC and later mathematical competence were invariant across boys and girls.

\section{Method}

\section{Participants}

The sample included 228 children, 115 girls and 113 boys, mean (standard deviation) age at study entry, girls $=2$ years 11 months 26 days ( 24 days); boys $=$ 2 years 11 months 28 days (24 days), $t(226)=.82$, $p=.41$. Participants were recruited through flyers distributed at preschools, doctors' offices, the local health department, and by word of mouth, from two Midwestern study sites, a small city and a rural tri-county area. To determine study eligibility, parents completed a telephone screening call and children with identified developmental, language or behavior impairments, whose families planned to move out of the area or whose primary language was not English, were not recruited. Participant retention ranged from $96 \%$ at age 3 years 9 months, to $92 \%$ at 5 years 3 months. The sample spanned a wide range of social risk, the families of $45 \%$ of female and $39 \%$ of male participants, $\chi^{2}(1)=.93, p=.34$ meeting eligibility for public medical assistance. Mean (standard deviation) years of maternal education did not differ between genders: boys $=14.53(2.19$; range $=9-21)$, girls $=14.84(2.40 ;$ range $=9-22): t(226)=1.01, p=.32$. In terms of ethnicity, $75 \%$ of girls were White, $6 \%$ were African American, 5\% were Hispanic, and $14 \%$ were multiracial, with these proportions being $77 \%, 5 \%, 10 \%$, and $8 \%$ in boys, $\chi^{2}(3)=3.50, p=.32$. By 5 years 3 months, the majority of children (64\%) were attending some form of early education, including preschool (38\%), kindergarten $(25 \%)$, Head Start $(5 \%)$, or other $(2 \%)$.

\section{Procedures}

Within 2 weeks of each child's third birthday, trained graduate assistants visited the family home, where University Institutional Review Board-approved study procedures were explained to the parent and written informed consent was obtained. A research assistant administered the Woodcock-Johnson III Brief Intelligence Assessment (Woodcock, McGrew, \& Mather, 2001) and the Test of Early Mathematics Achievement-3 (Ginsburg \& Baroody, 2003) to the child in a quiet area of the home. Approximately 1 week later, parents and children attended an assessment at a university-based laboratory. Here, the mother completed a detailed interview regarding the child's health and family background, while a research technician administered a comprehensive battery of EC tasks to the child. During follow-up visits to the laboratory, children were administered the Test of Early Mathematics Abilities (TEMA) and, at age 5 years 3 months, the Applied Problems subtest from the Woodcock-Johnson III (McGrew \& Woodcock, 2001). The laboratory visit lasted $1.5-2 \mathrm{hr}$, including time for a break and snack. Parents were compensated for their time and children received a small gift after each session.

\section{Measures}

EC at age 3 years - Measures of EC were chosen to represent putative components of working memory and inhibitory control and were selected specifically 
to vary in format and response demands to enable us to parse the critical, common latent variance associated with EC per se from the variance associated with task content features (see Wiebe et al., 2011, for further details). Although the battery also included measures selected to assess set shifting, these tasks showed floor effects and were not considered further. As is common in individual difference designs (Carlson, Moses, \& Claxton, 2004), measures were administered in a fixed order based on piloting to determine which task sequence best maintained interest. Task coding was completed by trained undergraduates who were blind to study hypotheses. For tasks that required coding or scoring, $20 \%$ of cases were randomly selected for independent cross-scoring, conducted at a later time using Noldus Observer software. Task completion rates were high $(91 \%-100 \%)$.

The first three tasks were chosen a priori to assess working memory, based on their common requirement to maintain information in mind in the service of task performance. In Delayed Alternation (adapted from Espy, 1999; Goldman, Rosvold, Vest, \& Galkin, 1971), children were instructed to retrieve a food reward from one of two testing wells covered with beige-colored cups. After each correct retrieval, the reward was switched to the opposite well so that children needed to remember the previous location and alternate their response to maximize their rewards. A 10-s delay was imposed between trials, during which the researcher verbally distracted the child. Once children had passed 3 training trails, up to 16 test trials were administered. If children made nine consecutive correct responses, the task was discontinued and the child was given credit for the remaining trials. The dependent variable for the task was the maximum length of consecutive incorrect responses subtracted from the maximum length of consecutive correct responses. Interrater reliability, based on cross-scoring for $20 \%$ of sessions, was $98 \%$.

In Nine Boxes (adapted from Diamond, Prevor, Callender, \& Druin, 1997), children were instructed to find cartoon figurines hidden in nine boxes that varied in color and lid shape, the most optimal strategy entailing an organized search of each box. After each selection, there was a 15-s delay during which the boxes were scrambled behind a screen. Up to 20 trials were administered, with administration ceasing after all nine figurines had been retrieved or after five consecutive errors. The dependent variable for this task was the child's longest run of consecutive correct responses. Inter-rater reliability was 100\%.

The Nebraska Barnyard (adapted from Noisy Book, Hughes, Dunn, \& White, 1998) was administered on a touch screen monitor using Perl (ActiveState Software, Vancouver, BC, Canada) software. Children were introduced to a $3 \times 3$ grid of colored squares (buttons) on the computer screen, each of which contained a picture of a farm animal. When children touched these buttons, they produced a corresponding animal noise. During training trials, children were instructed to press each button to build up a memory for the animal locations. Children who were unable to complete this phase of the task $(n=7)$ were assigned a 0 score. During subsequent test trials, the animal pictures were removed and children were required to respond to strings of animal names by pressing the corresponding colored buttons. Span length increased from 1 through 8, with administration ceasing after a child had failed all three trials at a particular span length. The dependent variable for this task consisted of correct responses and total presses summed across different span lengths. Performance was coded in Noldus, the mean interrater kappa being 99 .

Three tasks were selected to assess inhibitory control, based on their common requirement to suppress a prepotent tendency in service of task performance. The Shape School-Inhibit Condition (Espy, 1997) was programmed using the Eprime 1.1 (Psychology Software Tools, Pittsburgh, PA) software package and administered by computer. Stimuli were cartoon characters who varied by color: blue or red; shape: circle or square, and emotion: happy or sad. During 12 preliminary trials, children were asked to name the color of individual characters appearing successively on the screen as quickly and as accurately as possible. During the subsequent Inhibit condition (12 color naming and 6 response suppression trials), children were instructed to name happy-faced characters but to remain silent when sad-faced characters appeared. The dependent variable for the task was children's proportion of correct inhibit responses. Children who were unable to pass criterion trials $(n=47)$ were assigned a 0 score. Task performance was coded in Noldus Observer, with the mean interrater kappa being .92 .

In Big-Little Stroop (Kochanska, Murray, \& Harlan, 2000) children were told to name the smaller shapes embedded within line drawings of larger shapes (e.g., a butterfly, a flower). After a series of training trials, 24 test trials were presented, $50 \%$ of which were nonconflict trials, where the smaller pictures matched the larger shape, and $50 \%$ of which were conflict trials, where the shape pictures conflicted. Before the onset of each stimulus in EPrime, a brief $(750 \mathrm{~ms})$ priming stimulus of the larger shape was presented. The 
dependent variable for the task was the proportion of correct responses to conflict trials. The task was coded in Noldus, the interrater kappa being .91.

For the Go-No-Go task (adapted from Simpson \& Riggs, 2006), children were instructed to catch a series of colored fish by pressing a button on a response pad, but to avoid pressing the button when a shark stimulus appeared (25\% of trials). After each trial, feedback was presented in the form of a net, which broke if the child made an incorrect response to a shark. Stimuli were presented in Eprime for a maximum length of $1500 \mathrm{~ms}$, with an interstimulus interval of $100 \mathrm{~ms}$. The dependent variable, dPrime, calculated directly from computerized EPrime data, assessed children's ability to correctly discriminate between target and nontarget stimuli. In data from independent sample of 31 preschoolers, test-retest reliability over a span of 2 weeks was $87 \%$.

In the Modified Snack Delay task (adapted from Kochanska, Murray, Jacques, Koenig, \& Vandegeest, 1996; Korkman, Kirk, \& Kemp, 1998), children were instructed to remain still and silent with their hands positioned on a mat until the research assistant rang a bell. A handful of $M$ \& $M$ candies was placed under a transparent cup in front of the child. Over the course of the interval, the experimenter followed a scripted sequence of actions designed to distract the child (e.g., coughing, dropping a pencil, leaving the room for $90 \mathrm{~s}$ toward the end of the delay). For each 5-s interval, children were allocated 1 point each for standing still, keeping their hands on the mat, and remaining silent, the sum of these points serving as the dependent variable for the task. Therefore, the measure extracted from the Modified Snack Delay task was an index of motor inhibition, and not time to eat the snack used in the traditional task. Coding was conducted in Noldus, interrater reliability being $89 \%$.

Measures of mathematics achievement - The Test of Early Mathematics Ability-3 (Ginsburg \& Baroody, 2003) was administered in alternate forms at all study points. Items are presented verbally or from a picture-based response booklet and were drawn directly from the developmental literature on mathematics (e.g., Huttenlocher et al., 1994). The full TEMA score has been criticized as having limited utility in separating out different components of mathematics (Bliss, 2006). Given our specific interest in informal numeracy as a predictor of mathematics competence, we chose to parse the Informal Mathematics scale, consisting of items related to numbering, number comparisons, basic nonverbal and verbal calculation, and informal concepts, from the Formal Mathematics scale, consisting of items related to number literacy, number facts, formal calculation, and formal concepts. We used only the informal scale in our analysis at the 3 year 9 month (3.9) and 4 year 6 month (4.6) age points, in keeping with our aim of disentangling the relevance of EC and informal numeracy for later mathematics proficiency. At kindergarten age (5.3), the full TEMA score was used due to our interest in capturing global mathematics achievement as the measured outcome at this final time point. The TEMA shows high internal consistency (.92-96) and test-retest reliability (.82-.93), as well as robust correlations with other widely used measures of mathematics achievement ( $r=.54-.91$, Ginsburg \& Baroody, 2003). Although the Informal and Formal Scales are described in the manual, separate reliability coefficients for these scales are not provided.

The Woodcock-Johnson III Applied Problems subtest (McGrew \& Woodcock, 2001) assesses children's ability to apply mathematical knowledge to everyday story-based problems and was administered at age 5.3 to provide a broader and more comprehensive measure of children's mathematics achievement at this critical time of transition to formal education. Children respond verbally to story or picture-based items. Reliability coefficients of the Woodcock-Johnson Tests of Achievement III for younger ages range from .92 to .94 and performance on the battery correlates well with other general measures of academic achievement.

Early language ability - Children's verbal comprehension abilities were assessed at age 3 years with the Verbal Comprehension subtest from the Woodcock-Johnson III (Woodcock et al., 2001). This subtest comprises four components: picture vocabulary, synonyms, antonyms, and verbal analogies. Reliability coefficients in this age group range from .88 to .93 .

Processing speed - Processing speed was assessed using the Visual Matching subtest from the Woodcock-Johnson III. The subtest requires children to match as many numbers as possible within a specified time frame. Reliability coefficients in this age group range from .73 to .80 .

\section{Statistical Methods}

Descriptive analyses were performed in SAS 9.2 (SAS Institute, Cary, NC) whereas structural equation modeling (SEM) was conducted in Mplus 6 (Muthén \& Muthén, Los Angeles, CA). Analysis proceeded in three phases. First, $t$ tests and corre- 
lations were used to provide a general indication of growth and variability in informal mathematics achievement, as well as an indication of the strength of associations between measures collected at the various study time points. Second, SEM was used to examine direct and indirect associations between latent EC and mathematics performance across the preschool period. We previously used CFA of the same EC tasks presented here to test different models of latent EC in this sample at age 3 years, including a model with working memory parsed from inhibition, and found that a single latent EC factor is the statistically favored model (Wiebe et al., 2011). In the current study, we examined the associations between this empirically identified single EC latent and informal mathematics performance, assessed with the TEMA at ages 3.9 and 4.6. Thereafter, we regressed latent mathematics proficiency at the final study time point (5.3) on EC at 3 years to determine the direct association between early EC and kindergarten mathematics achievement. The Applied Problems subtest and TEMA total score were modeled as a single latent at age 5.3 to provide a more reliable indicator of general mathematics proficiency at this important time of transition to kindergarten. Next, we examined the potential mediating effect of informal mathematics skills at 3.9 and 4.6 on relations between EC, assessed at age 3, and mathematics proficiency, assessed at age 5.3. Using chi-square difference tests, models including direct paths between EC and mathematics achievement were compared to nested models with these paths set to zero. If a path can be dropped without a significant drop in the model chi-square, then the more parsimonious model is preferred (Brown, 2006).

Given robust associations between socioeconomic status (SES) and mathematics achievement (Jordan \& Levine, 2009), as well our desire to characterize the unique relations between early EC and later mathematics, family SES, which was modeled as a latent construct incorporating eligibility for free or reduced lunch, household crowding (number of residents per rooms in the home; Evans, 2003), and maternal education (scored on a 5-point scale of no high school education, high school or general education diploma, some college or associate's degree, bachelor's degree or graduate degree) was introduced as a covariate. Verbal comprehension and processing speed measures from age 3 were also included. Models incorporating pathways between these measures, early EC and later mathematics proficiency were compared using chi-square difference tests to identify the model with the greatest parsimony.
Third, we tested whether or not the longitudinal relations among early EC, mathematics proficiency, informal mathematics, SES, language and processing speed were similar for boys and girls. To test measurement model invariance, we successively constrained the factor structure (configural invariance), indicator loadings (metric invariance), indicator means (scalar invariance) and indicator errors and intercepts of the EC and mathematics latents to be fixed and equal across the genders. A significant drop in model fit with the imposition of an equality constraint indicates that the constructs are not measured similarly in the two groups (Brown, 2006). Likewise, invariance of the structural part of model was tested by examining discrepancies in fit after constraining successive pathways to be equal, a drop in chi-square indicating that the strength of the association differs between groups. A criterion $p$ value of .05 was used for all analyses.

\section{Results}

\section{Growth in Mathematics Over Time}

Table 1 describes the performance of boys and girls on measures of EC, verbal comprehension and processing speed at 3 years and measures of mathematics skill at 3.9, 4.6, and 5.3. Girls and boys differed only in their performance on the Modified Snack Delay task, $t(212)=2.02, p<.05$. Children's mean performance on the TEMA increased dramatically with age and there were no sex differences in mathematics performance at any time point.

\section{Bivariate Relations Between Measures of Early EC and Later Mathematics Achievement}

Table 2 shows the correlations between measures of EC administered at 3 years, intervening informal mathematics and later mathematics achievement. Correlations between Big-Little Stroop, Shape School Inhibit, and Nebraska Barnyard performance and mathematics measures collected across the preschool period were more robust $(r s=.22-.42)$, although other EC measures also showed associations with later mathematics achievement $(r s=.07-.21)$. High correlations between mathematics outcome measures also suggested intraindividual stability in mathematics performance over time ( $r \mathrm{~s}=.48-.73$ ). Finally, EC and mathematics measures showed moderate associations with verbal comprehension and visual matching at 3 years $(r s=.17-.47)$ and modest, but signifi- 
Table 1. Mean Performance on Executive Control (EC) and Mathematics Measures in Preschool Girls and Boys

\begin{tabular}{|c|c|c|c|c|c|c|}
\hline Variable & \multicolumn{2}{|c|}{$M(S D)$ girls } & \multicolumn{2}{|c|}{$M(S D)$ boys } & \multicolumn{2}{|c|}{$t(d f)$} \\
\hline \multicolumn{7}{|l|}{ EC (3 years) } \\
\hline Delayed Alternation maximum correct run-incorrect run & -0.07 & $(3.81)$ & -0.68 & $(3.40)$ & 1.28 & $(225)$ \\
\hline 9 Boxes maximum correct run & 4.65 & $(1.65)$ & 4.50 & $(1.52)$ & 0.75 & $(226)$ \\
\hline Nebraska Barnyard summary score & 1.21 & $(.64)$ & 1.12 & $(.57)$ & 1.05 & $(218)$ \\
\hline Shape School inhibit \% correct & 0.39 & $(.43)$ & 0.33 & $(.40)$ & 1.11 & $(193)$ \\
\hline Snack Delay epochs without movement & 38.58 & $(23.28)$ & 31.94 & $(24.74)$ & 2.02 & $(212)^{*}$ \\
\hline \multicolumn{7}{|l|}{ Mathematics achievement measures } \\
\hline TEMA informal items 3 years 9 months & 6.35 & $(3.82)$ & 5.67 & $(4.17)$ & 1.27 & $(216)$ \\
\hline TEMA informal items 4 years 6 months & 11.2 & $(4.50)$ & 11.58 & $(.05)$ & -0.51 & $(210)$ \\
\hline TEMA total score 5 years 3 months & 18.63 & $(8.01)$ & 20.59 & $(9.62)$ & -1.61 & $(208)$ \\
\hline
\end{tabular}

TEMA = Test of Early Mathematics Abilities; WJ = Woodcock-Johnson III.

$* p<.05$

cant correlations with socio-demographic measures $(r s=.14-.28)$. The pattern and magnitude of intercorrelations were similar for boys and girls.

\section{Relations Between Latent EC at 3 Years and Later Informal Mathematics Skills}

The first step in the SEM analysis was to examine the association between the latent measure of EC identified at 3 years by Wiebe et al. (2011) and children's later informal mathematics performance on the TEMA. There were significant direct associations between EC at 3 and TEMA informal scores at $3.9(\beta=.59, p<.001)$ and $4.6(\beta=.57, p<.001)$. Specifically, with each standard deviation increase in latent EC at age 3 years, children's TEMA informal scores were higher by 2.36 points at age 3.9 and by 3.05 points at age 4.6. With subsequent control for informal TEMA scores at age 3.9, the association between EC at age 3 years and informal scores at age 4.6 remained significant $(\beta=.22, p<.01), \chi^{2}(26)=35.4$, $p=.01$; root mean square error of approximation $($ RMSEA $)=.04$; comparative fit index $(\mathrm{CFI})=.97$, despite the strong relation between children's TEMA performance at 3.9 and $4.6(\beta=.60, p<.001)$. The indirect effect of early EC on informal scores at 4.6 via TEMA performance at 3.9 was also significant $(\beta=.35, p<001)$. As a stronger test for mediation, we compared this full model, including paths between EC and TEMA informal mathematics at ages 3.9 and 4.6, to a nested model with the path between EC and performance at 4.6 set to zero. Although both mod- els showed acceptable fit, a drop in chi-square between the full model and the nested model indicated the more parsimonious mediational model provided a worse fit to the data than the model that allowed for an independent direct path between early EC and informal mathematics at 4.6., $\chi^{2} \Delta(1)=7.75, p<.01$, RM$\mathrm{SEA}=.05, \mathrm{CFI}=.95$.

\section{Relations Between Latent EC at 3 Years and Mathematics Achievement at Kindergarten Age}

The second step in the analysis involved extending predictive associations out to general mathematics proficiency at age 5.3. The correlation between the mathematics measures at 5.3, namely the WoodcockJohnson III-Applied Problems subtest and the TEMA total score (including both informal and formal items), was high $(r=.70)$. A latent variable with two indicators is feasible given that there is an additional latent factor (EC) in this model (Kline, 2011). Therefore, we constructed a latent variable for mathematics at age 5.3 based on these measures. As this general mathematics proficiency factor comprises only two indicators, factor loadings were held equal for model identification purposes.

The direct relation between latent EC at age 3 years and latent general mathematics proficiency at age 5.3 was strong, with EC explaining $41 \%$ of the variance in general mathematics proficiency over 2 years later $(\beta=.64, p<.001), \chi^{2}(27)=29.37, p=.35$; RMSEA $=.02$; $\mathrm{CFI}=.99$. To examine whether or not this association was accounted for by intervening informal math- 


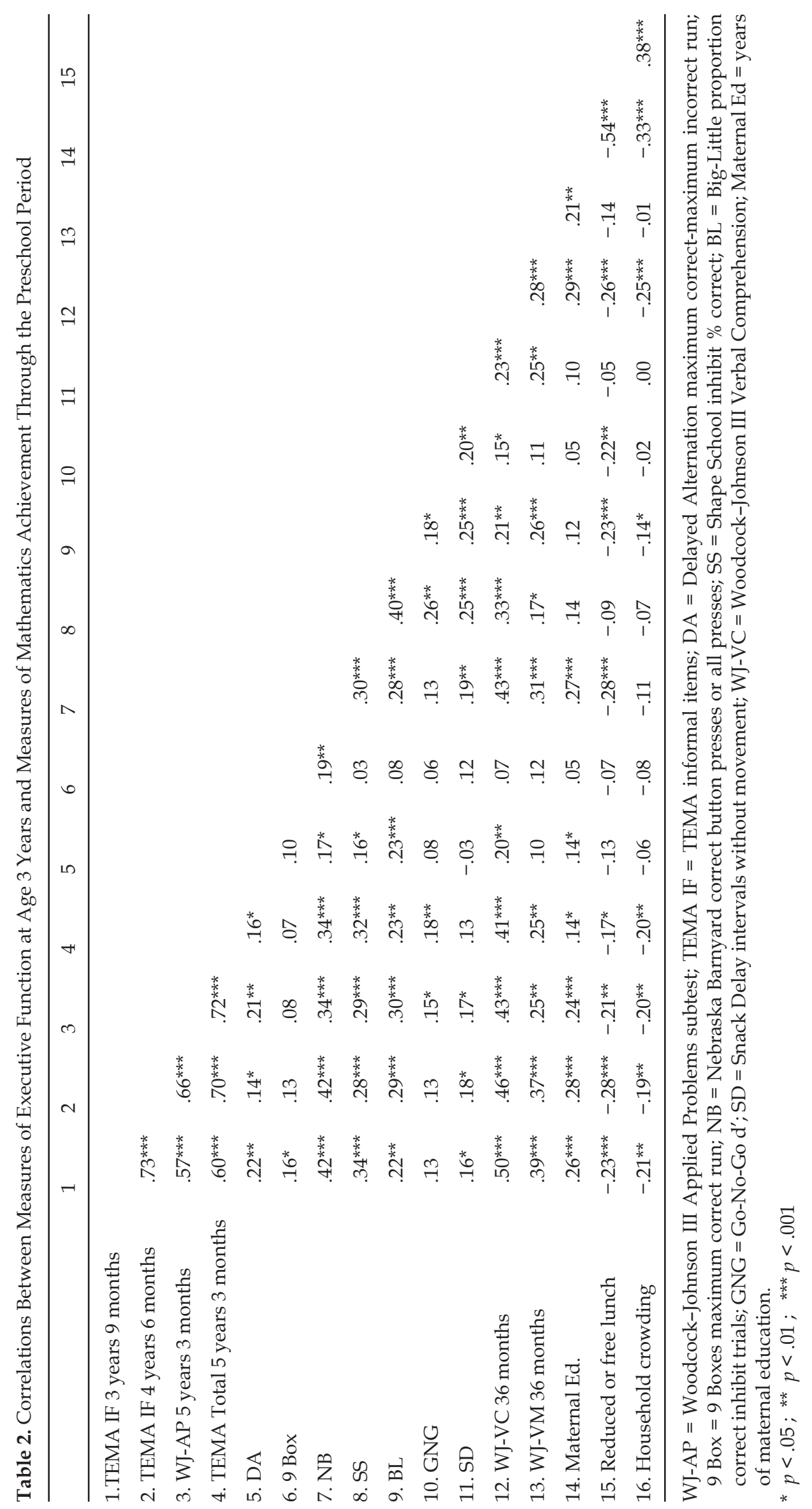




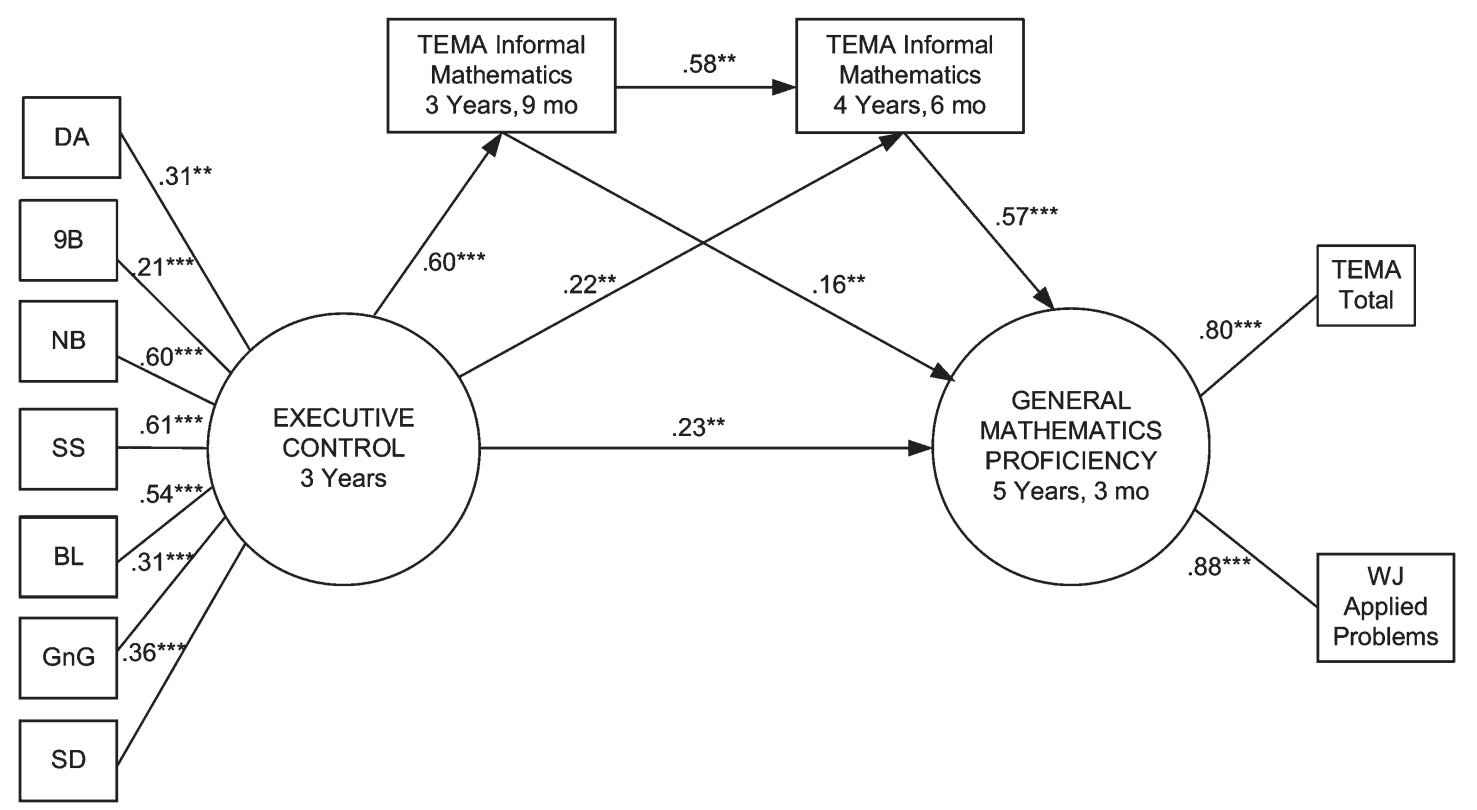

Figure 1. Relation between children's early executive control and mathematics achievement at kindergarten entry age after controlling for informal mathematics at 3 years 9 months, and 4 years 6 months. WJ: Woodcock-Johnson III; TEMA = Test of Early Mathematics Abilities. ${ }^{* *} p<.01 ;{ }^{* * *} p<.001$

ematics performance, we introduced TEMA informal mathematics scores from ages 3.9 and 4.6 into the model. Figure 1 shows that the relation between EC at 3 years and mathematics at 5.3 remained significant $\left(\beta=.23, p<.001, \chi^{2}(41)=46.65, p=.25\right.$; RMSEA $=.02$; $\mathrm{CFI}=.99$. The indirect effect of early EC via informal mathematics at ages 3.9 and 4.6 was also significant $(\beta=.20, p<.001)$. As a further test for mediation, we set the path between EC at 3 years and mathematics at 5.3 to 0 . The removal of this pathway resulted in a significant drop in model fit, $\chi^{2} \Delta(1)=7.1, p<.01$; $\mathrm{CFI}=.98$, RMSEA $=.04$, indicating that intervening informal mathematics did not fully mediate the relation between EC at 3 and mathematics at 5.3. The $R^{2}$ value indicated that $70 \%$ of the variance in kindergarten mathematics proficiency was accounted for by early EC and intervening informal mathematics.

\section{Effects of Covariate Adjustment on Relations Be- tween EC and Mathematics}

Next, we tested the effects of SES, verbal comprehension and processing speed, measured at age 3 years, on associations between early EC and mathematical performance. The first model included latent SES as a predictor of both EC at 3 years and of mathematical proficiency at 5.3. Although the model revealed a strong relation between SES and EC $(\beta=.52$, $p<.001)$, SES was not associated directly with mathematics proficiency $(\beta=-.07, p=.39), \chi^{2}(72)=83.58$, $p=.17$; RMSEA $=.03 ; \mathrm{CFI}=.99$. Instead, the indirect relation between SES and age 5.3 mathematics proficiency via early EC was significant $(\beta=.15, p<.05)$, indicating that EC mediated the relation between SES and mathematics. Accordingly, fixing the direct pathway between EC and mathematics at 5.3 to 0 resulted in a drop in model fit, $\chi^{2} \Delta(1)=6.64, p<.001$; RM$\mathrm{SEA}=.03 ; \mathrm{CFI}=.98$.

After additional control for verbal comprehension and visual matching scores, the unstandardized pathway between early EC and later mathematics at 5.3 was attenuated to a trend level $(\beta=.39$, $S E=.17, p=.07)$. However, the direct paths from language comprehension $(\beta=.01, S E=.08, p>.10)$ and visual matching $(\beta=-.15, S E=.08, p>.05)$ to mathematics proficiency at 5.3 were not significant. Moreover, setting the pathway between EC and mathematics proficiency to 0 resulted in a significant model fit reduction, $x^{2} \Delta=5.39, p<.05$, the sum of these findings indicating that SES, verbal skills, and processing speed at 3 were mediated by EC and informal numeracy skills. In the interests of parsimony, nonsignificant pathways were trimmed out of the final model with no reduction in model fit. The $R^{2}$ estimate for latent mathematics proficiency in this final model was .73.

\section{Sex Differences in the Relations Between EC and Mathematics}

Invariance for boys and girls held at all levels of the measurement model. Specifically, the configural 


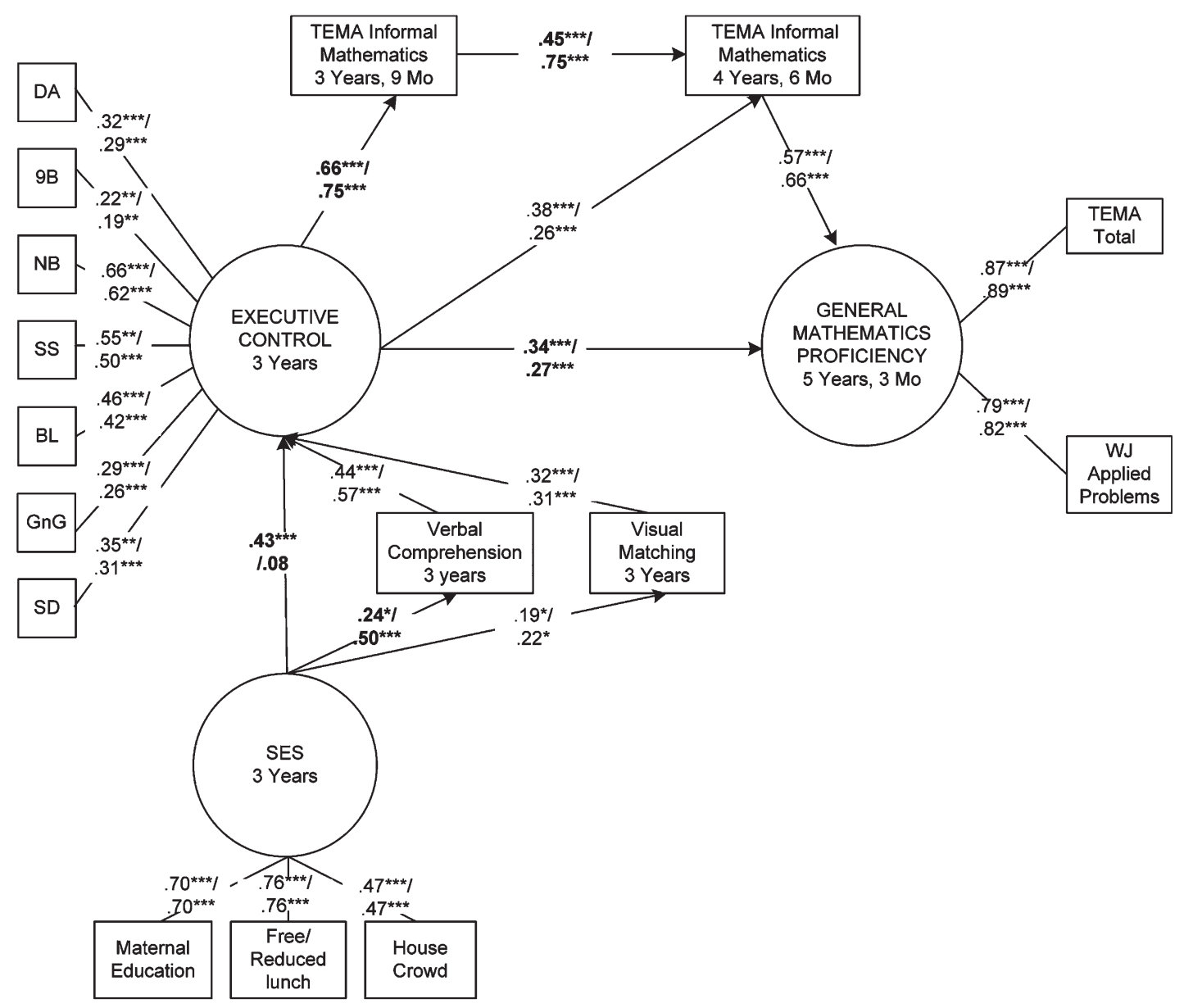

Figure 2. Relations between language, processing speed, SES, executive control and mathematics over the preschool period in girls and boys. Figure illustrates the standardized loadings for the task for girls or boys. Due to differences in standard error, standardized loadings may appear different between genders when they are held equal. Parameters in bold reflect significant sex differences in the strength of associations. ${ }^{*} p<.05 ;{ }^{* *} p<.01 ;{ }^{* * *} p<.001$

model, factor loadings, indicator intercepts, and indicator residuals of the EC latent and mathematics proficiency latent could all be constrained to be equal across the genders without a significant reduction in model fit. Structural invariance tests showed that boys and girls did not differ significantly in the variance or means of their latent EC or mathematics proficiency. However, fixing the path between EC and mathematics proficiency at 5.3 to be equal between the genders led to a significant reduction in model fit, $\chi^{2}(1)=7.16, p<.01$, indicating that this relation was stronger for girls, whereas the relation between EC and informal mathematics at age 3.9 was stronger for boys, $\chi^{2}(1)=4.08, p<.05$. Similarly, fixing the path between informal mathematics at age 3.9 and 4.6 to be equal led to a significant reduction in model fit, with this relation being stronger in boys than in girls, $\chi^{2}(1)=4.79, p<.05$. Finally, the direct association between SES and EC was stronger in girls, $\chi^{2}(1)=5.58$, $p<.05$, and not significant in boys. In contrast, the relation between SES and verbal skills was stronger for boys, $\chi^{2}(1)=4.24, p<.05$. The final, partially invariant model of relations between EC and mathematics for boys and girls is shown in Figure 2. Apart from the pathways that differed significantly for boys and girls (in bold), all illustrated model parameters were held equal between the genders.

\section{Discussion}

Knowledge of the fundamental skills that prepare children for formal academic instruction is critical for optimizing their achievement trajectories. This study ties together two broad, diverse literatures on EC and early mathematics, examining the relative importance of these constructs for later mathematics achievement, as well as potential sources of individual variation in these relations. The longitudinal design of the study revealed strong and consistent relations between EC measured as early as 3 years and mathematics achievement over 2 years later even af- 
ter accounting for informal mathematics skills at ages 3.9 and 4.6, as well as SES, language, and processing speed. EC was related not only to mathematics achievement at 5.3 but also to relatively basic and primarily nonverbal informal mathematics skills assessed at earlier time points. Although the important role of informal mathematics in predicting later mathematics proficiency should be acknowledged, the sheer persistence of the relation between EC at age 3 and mathematics performance at kindergarten age after controlling for other important predictors supports the idea that EC skills form a critical foundation for academic skill acquisition in both boys and girls and that they contribute importantly and uniquely to children's readiness for formal mathematics instruction.

Although this study is, to our knowledge, the first to show that EC assessed as early as 3 years is linked independently with later mathematics achievement over and above rudimentary numeracy skills, findings are similar to those for older children (Fuchs et al., 2010; Kroesbergen et al., 2009). For instance, Kroesbergen et al. (2009) showed that performance on individual EC measures at school entry accounted for approximately $45 \%$ of the variance in children's concurrent mathematics skills. Children's performance on a subitizing task also predicted mathematics achievement, but it accounted for only a small proportion of the variance $(2 \%)$ over and above measures of EC. Coupled with these findings from older children, current study findings suggest that a child's executive ability at an extremely young age is an important marker for later mathematics achievement above and beyond their informal grasp of numeracy.

What is less clear from this study is the precise nature of the mental processes that link EC and mathematics. One potential explanation for the utility of EC for predicting later mathematics independent of intervening numeracy performance is that EC may enable children to deploy their knowledge more effectively. Although children may possess the conceptual and procedural knowledge necessary to perform a task, they sometimes struggle to apply this knowledge to specific problems (Blair, Knipe, \& Gamson, 2008). Such dissociations between knowledge and action are common in preschoolers and are a prototypic hallmark for prefrontal lesions and resulting executive dysfunction in adults (Luria, 1973; Milner, 1963). Although preschoolers may possess a platform of informal mathematical knowledge, EC may assist them to respond to changing task demands, maintain context or problem-specific information active in working memory and inhibit distracting in- formation. Similarly, children with better EC skills may rally their attention resources more effectively for tasks that might not be intrinsically motivating. Indeed, EC may be taxed to a greater extent in young children, who do not have a strong foundation of procedural knowledge upon which to draw. This argument is in keeping with fMRI studies showing that neural regions associated with EC are activated to a greater degree in children than in adults (Houde, Rossi, Lubin, \& Joliot, 2010). Essentially, children may need to exert more cognitive effort because they do not possess coherent mnemonic representations of mathematical information to bring to bear on difficult tasks. Of course, there is also the possibility that the relations between EC and mathematics may be reciprocal (e.g., see Welsh et al., 2010) as stronger conceptual and procedural knowledge may free up EC resources that can then be devoted to mathematical tasks.

A second possibility is that executive capabilities are actually involved in the fundamental acquisition of mathematical facts and concepts. Imaging studies in adults have shown that EC and mathematics tasks often activate similar cortical regions (Gruber \& Goschke, 2004; Nieder \& Dehaene, 2009). The intraparietal sulcus appears important for the early processing of numerical information, whereas groups of neurons in the prefrontal cortex (PFC) and intraparietal sulcus of the monkey appear to be arranged sequentially to respond to growing magnitudes (Nieder \& Miller, 2004). However, the PFC alone is specialized for learning to pair numeric magnitudes with semantic representations. Diester and Nieder (2007) showed that with repeated pairing of a nonverbal numerosity and an abstract Arabic number symbol, PFC neurons progressively became tuned to specific magnitudes, regardless of whether they were presented symbolically or as nonverbal representations. This pattern mirrors the expected transition from informal number sense to the acquisition of symbolic mathematics that occurs through the preschool and early school years. As children gain more familiarity with numeric symbols, the representation of magnitude appears to move to the posterior neural regions (Houde et al., 2010). Given the central role of the PFC in EC, some of the early overlap in EC and numeracy may also reflect overlapping neural networks that are undergoing substantive development and differentiation during the preschool period. Of course, these differing explanations for the overlap between EC and mathematics are not incompatible, with EC potentially being related both to the acquisition and to the application of mathematical knowledge. Neuroimag- 
ing studies with young children will help to address better these alternative explanations for the overlap between early EC and mathematics.

Aside from the clear relations between EC and mathematics, there were strong correlations between latent EC and early verbal comprehension $(r=.60)$ and EC and processing speed $(r=.50)$, highlighting the interconnected nature of these core cognitive abilities in this young age group. Indeed, correlations between individual measures of EC and language were as strong as those between the EC measures themselves, with early language abilities explaining approximately $45 \%$ of the variance in latent EC (although this design does not lend itself to testing a reverse association). After accounting for $\mathrm{EC}$, language, and processing speed were no longer associated directly with mathematics performance, perhaps indicating that more proficient language and processing speed facilitate EC task performance by enabling children to integrate and represent rules and relationships more effectively and to process or rehearse information, which in turn supports their mathematics performance. Certainly, language is acknowledged theoretically to be critical for self-regulation (Barkley, 1997; Vygotsky, 1978) and no doubt assists children to understand and engage with EC tasks.

Findings also hinted at subtle sex differences in the pattern of linkages between early EC and later mathematics competence. Although there were independent associations between EC at age 3 years and kindergarten mathematics achievement for both genders, the direct association between early EC and later mathematics was stronger in girls. In contrast, boys drew more strongly on informal mathematics abilities to support mathematics acquisition. These subtle differences may preface sex differences in middle childhood. For instance, using latent modeling methods, Brunner, Krauss, and Kunter (2008) showed that boys drew on domain-specific mathematics abilities to a greater extent than girls, who tended to draw on more general cognitive skills when solving mathematics problems. Similarly, boys prefer to retrieve mathematics facts directly whereas girls take a more effortful, mastery-based approach to learning (Carr \& Davis, 2001; KenneyBenson, Pomerantz, Ryan, \& Patrick, 2006). In addition, although SES was more directly associated with EC in girls, it was more closely associated with language in boys, perhaps suggesting that boys are differentially advantaged by a boost in language abilities associated with a more financially advantaged home environment.
Findings have implications for the way in which we view numeracy in early childhood. Researchers have argued that difficulties in learning mathematics occur because of a deficit in the core number system (Butterworth, 1999; Shalev, 1997). This argument is supported by the fact that children with MLD perform more poorly on tests of subitizing or number line estimation (Geary et al., 2009). However, consistent associations between early EC and later mathematics achievement even after accounting for intervening informal numeracy, early vocabulary, processing speed, SES, and, in other studies, early reading ability (Bull et al., 2008; Clark et al., 2010) suggest the potential for another pathway to difficulties in mathematics acquisition related to weaknesses in EC. Importantly, our results indicate that preschool education mathematics curricula would benefit from a two-tiered approach, targeting not only basic numeracy but also EC. Each plays a distinct role in predicting later mathematics achievement. Conceivably, EC will play a large role when children are mastering new mathematical skills, when information is novel and not easily retrieved from memory and when children are required to transfer learning from one problem to another. However, given that acquisition of mathematics skills is hierarchical, with early skills and concepts underpinning those taught later in the curriculum, initially discrete EC-related difficulties in learning basic mathematics facts and procedures likely will have cascading implications, affecting subsequent learning and achievement, as well as motivation and confidence, as children mature.

In terms of practical implications, despite the difficulties inherent in assessing children at such an early age, the assessment of EC at a very early time points may presage lower mathematics achievement around the time of formal school entry, and thus might be useful in identifying children for targeted intervention. Our latent variable approach no doubt was beneficial in revealing these strong associations in that this method essentially isolates the shared variance among tasks from measurement error or specific task properties. In clinical or educational settings, multiple measures across different contexts may be necessary to achieve a faithful representation of the very young child's executive competencies. Based on the strong associations shown here, interventions targeted at improving early EC likely will have downstream effects on academic achievement, with early EC intervention programs already showing promise in at-risk cohorts (Bierman, Nix, Greenberg, Blair, \& Domitrovich, 2008). Interestingly, the relation between early SES and mathematics appeared to be me- 
diated by EC, and, in boys especially, by early language skills, suggesting that boosting children's early EC may also help to buffer social risk. Research examining the more proximal and specific factors (e.g., access to material learning resources, parental investment) that our more distal measure of SES may reflect is necessary if we are to learn how best to support EC and mathematical competence.

Future studies incorporating experimental or intervention-based designs are needed to illuminate the ways in which these constructs interact to support mathematics growth, to better understand whether or not the relation of early EC to later mathematics is indeed causal, including whether spatial or reading abilities may explain some of these associations, as well as to determine whether or not early strength in EC might assist children to overcome the effects of broad social risk on mathematics achievement. Similarly, there is a need for standardized measures that allow for the parsing of specific informal numeracy skills to better articulate these early associations. Nonetheless, the consistent relations found in this study highlight the important potential role of early EC assessment in helping to predict how children might cope with the critical transition to formal mathematics instruction.

\section{References}

Aunola, K., Leskinen, E., Lerkkanen, M., \& Nurmi, J. (2004). Developmental dynamics of math performance from preschool to Grade 2. Journal of Educational Psychology, 96, 699-713. doi:10.1037/0022-0663.96.4.699

Barkley, R. A. (1997). Behavior inhibition, sustained attention and executive functions: Constructing a unified theory of ADHD. Psychological Bulletin, 121, 65-94.

Bell, M. A., Wolfe, C. D., \& Adkins, D. R. (2007). Frontal lobe development in infancy and early childhood. In D. J. Coch, K. W. Fisher, \& G. Dawson (Eds.), Human behavior, learning and the developing brain (pp. 247-276). New York: Guilford.

Bierman, K. L., Nix, R. L., Greenberg, M. T., Blair, C., \& Domitrovich, C. E. (2008). Executive functions and school readiness intervention: Impact, moderation, and mediation in the Head Start REDI program. Development and Psychopathology, 20, 821-843. doi:10.1017/ S0954579408000394

Blair, C., Knipe, H., \& Gamson, D. (2008). Is there a role for executive functions in the development of mathematics ability. Mind, Brain and Education, 2, 80-89.

Bliss, S. (2006). Test of Early Mathematics Ability-Third Edition. Journal of Psychoeducational Assessment, 24, 8591. doi:10.1177/0734282905282839

Brown, T. (2006). Confirmatory factor analysis for applied re- search. New York: Guilford.

Brunner, M., Krauss, S., \& Kunter, M. (2008). Gender differences in mathematics: Does the story need to be rewritten? Intelligence, 36, 403-421. doi:10.1037/00220663.96.4.699

Bull, R., Espy, K. A., \& Wiebe, S. A. (2008). Short-term memory, working memory, and executive functioning in preschoolers: Longitudinal predictors of mathematical achievement at age 7 years. Developmental Neuropsychology, 33, 205-228. doi:10.1080/87565640801982312

Bull, R., Espy, K. A., Wiebe, S. A., Sheffield, T. D., \& MizeNelson, J. (2011). Using confirmatory factor analysis to understand executive control in preschool children: Sources of variation in emergent mathematic achievement. Developmental Science, 14, 679-692. doi:10.1111/ j.1467-7687.2010.01012.x

Bull, R., Johnston, R. S., \& Roy, J. (1999). Exploring the roles of the visual-spatial sketch pad and central executive in children's arithmetical skills: Views from cognition and developmental neuropsychology. Developmental Neuropsychology, 15, 421-442.

Butterworth, B. (1999). The mathematical brain. London: Macmillan.

Carlson, S. M., Moses, L. J., \& Claxton, L. J. (2004). Individual differences in executive functioning and theory of mind: An investigation of inhibitory control and planning ability. Journal of Experimental Child Psychology, 87, 299-319. doi:10.1016/j.jecp.2004.01.002

Carr, M., \& Davis, H. (2001). Gender differences in arithmetic strategy use: A function of skill and preference. Contemporary Educational Psychology, 26, 330-347.

Carr, M., \& Jessup, D. L. (1997). Gender differences in first grade mathematics strategy use: Social and metacognitive influences. Journal of Educational Psychology, 89, 318-328.

Clark, C. A., Pritchard, V. E., \& Woodward, L. J. (2010). The development of children's executive function predicts early mathematics achievement. Developmental Psychology, 46, 1176-1191. doi:10.1037/a0019672

Dehaene, S. (1997). The number sense. New York: Oxford University Press.

Denton, K., \& West, J. (2002). Children's reading and mathematics achievement in kindergarten and first grade. Washington, DC: U.S. Department of Education, NCES.

Diamond, A., Prevor, M. B., Callender, G., \& Druin, D. P. (1997). Prefrontal cortex cognitive differences in children treated continuously for PKU. Monographs of the Society for Research in Child Development, 62.

Diester, I., \& Nieder, A. (2007). Semantic associations between signs and numerical categories in the prefrontal cortex. PLoS Biology, 5, 2684-2694. doi:10.1371/journal. pbio.0050294

Duncan, G. J., Dowsett, C. J., Claessens, A., Magnusen, K., Huston, A. C., Klebanov, P. K., et al. (2007). School readiness and later achievement. Developmental Psychology, 43, 1428-1446. doi:10.1037/0012-1649.43.6.1428 
Durston, S., Davidson, M. C., Tottenham, N., Galvan, A., Spicer, J. A., Fossella, J. A., et al. (2006). A shift from diffuse to focal cortical activity with development. Developmental Science, 9, 1-20.

Espy, K. A. (1997). The Shape School: Assessing executive function in preschool children. Developmental Neuropsychology, 13, 495-499.

Espy, K. A. (1999). Executive functioning in preschool children: Performance on A-not-B and other delayed response format tasks. Brain and Cognition, 41, 178-199.

Evans, G. W. (2003). A multimethodological analysis of cumulative risk and allostatic load among rural children. Developmental Psychology, 39, 924-933. doi:10.1037/00121649.39.5.924

Fuchs, L. S., Geary, D. C., Compton, D. L., Fuchs, D., Hamlett, C. L., \& Bryant, J. D. (2010). The contributions of numerosity and domain-general abilities to school readiness. Child Development, 81, 1520-1533.

Gallistel, C. R., \& Gelman, R. (1992). Preverbal and verbal counting and computation. Cognition, 44, 43-74.

Garon, N., Bryson, S. E., \& Smith, I. M. (2008). Executive function in preschoolers: A review and integrative framework. Psychological Bulletin, 134, 31-60. doi:10.1037/0033-2909.134.1.31

Geary, D. C. (1994). Children's mathematical development: Research and practical applications. Washington, DC: American Psychological Association.

Geary, D. C., Bailey, D. H., \& Hoard, M. K. (2009). Predicting mathematical achievement and mathematical learning disability with a simple screening tool: The number sets test. Journal of Psychoeducational Assessment, 27, 265279. doi:10.1177/0734282908330592

Geary, D. C., Hoard, M. K., Byrd-Cracen, J., Nugent, L., \& Numtee, C. (2007). Cognitive mechanisms underlying achievement deficits in children with mathematical learning disability. Child Development, 78, 1343-1359.

Gelman, R., \& Galistel, C. R. (1978). The child's understanding of number. Cambridge, MA: Harvard University Press.

Gersten, R., Jordan, N. C., \& Flojo, J. R. (2005). Early identification and interventions for students with mathematics difficulties. Journal of Learning Disabilities, 38, 293304.

Ginsburg, H. P., \& Baroody, A. J. (2003). Test of Early Mathematics Achievement-3. Austin, TX: Pro-Ed.

Goldman, P. S., Rosvold, H. E., Vest, B., \& Galkin, T. W. (1971). Analysis of the delayed alternation deficit produced by dorsolateral prefrontal lesions in the rhesus monkey. Journal of Comparative and Physiological Psychology, 77, 212-220.

Gruber, O., \& Goschke, T. (2004). Executive control emerging from dynamic interactions between systems mediating language, working memory and attentional processes. Acta Psychologica, 115, 105-121. doi:10.1016/j. actpsy.2003.12.003

Halberda, J., Mazzocco, M. M. M., \& Feigenson, L. (2008).
Individual differences in non-verbal number acuity correlate with maths achievement. Nature, 455, 665-668. doi:10.1038/nature07246

Houde, O., Rossi, S., Lubin, A., \& Joliot, M. (2010). Mapping numerical processing, reading, and executive functions in the developing brain: A meta-analysis of 52 studies including 842 children. Developmental Science, 13, 876-885. doi:10.1111/j1467-7687.2008.00938.x

Hughes, C., Dunn, J., \& White, A. (1998). Trick or treat? Uneven understanding of mind and emotion and executive dysfunction in "hard to manage" preschoolers. Journal of child psychology and psychiatry, 39, 981-994.

Huizinga, M., Dolan, C. V., \& van der Molan, M. W. (2006). Age-related changes in executive function: Developmental trends and a latent variable analysis. Neuropsychologia, 44, 2017-2036. doi:10.1016/j.neuropsychologia.2006.01.010

Huttenlocher, J., Jordan, N. C., \& Levine, S. C. (1994). A mental model for early arithmetic. Journal of Experimental Psychology: General, 123, 284-296.

Jordan, N. C., Glutting, J., \& Ramineni, C. (2010). The importance of number sense to mathematics achievement in first and third grades. Learning and Individual Differences, 20, 82-88. doi:10.1016/j.lindif.2009.07.004

Jordan, N. C., Kaplan, D., Ramineni, C., \& Locuniak, M. N. (2009). Early math matters: Kindergarten number competence and later mathematics outcomes. Developmental Psychology, 45, 850-867. doi:10.1037/a0014939

Jordan, N. C., \& Levine, S. C. (2009). Socioeconomic variation, number competence, and mathematics learning difficulties in young children. Developmental Disabilities Research Reviews, 15, 60-68. doi:10.1002/ddrr.46

Kenney-Benson, G. A., Pomerantz, E. M., Ryan, A. M., \& Patrick, H. (2006). Sex differences in math performance: The role of children's approach to schoolwork. Developmental Psychology, 42, 11-26. doi:10.1037/00121649.42.1.11

Kline, R. B. (2011). Principles and practice of structural equation modeling. New York: Guilford.

Kochanska, G., Murray, K. T., \& Harlan, E. T. (2000). Effortful control in early childhood: Continuity and change, antecedents, and implications for social development. Developmental Psychology, 36, 220-232. doi:10.1037/00121649.36.2.220

Kochanska, G., Murray, K. T., Jacques, T. Y., Koenig, A. L., \& Vandegeest, K. A. (1996). Inhibitory control in young children and its role in emerging internalization. Child Development, 67, 490-507.

Korkman, M., Kirk, U., \& Kemp, S. (1998). NEPSY: A developmental neuropsychological assessment. Boston: The Psychological Association.

Krajewski, K., \& Schneider, W. (2009). Early development of quantity to number-word linkage as a precursor of mathematical school achievement and mathematical difficulties: Findings from a four-year longitudinal study. Learning and Instruction, 19, 513-526. 
Kroesbergen, E. H., Van Luit, J. E. H., van Lieshot, E. C. D. M., Van Loosbroek, E., \& Van de Rijt, B. A. M. (2009). Individual differences in early numeracy: The role of executive functions and subitizing. Journal of Psychoeducational Assessment, 27, 226-236. doi:10.1177/0734282908330586

La Paro, K. M., \& Pianta, R. C. (2000). Predicting children's competence in the early school years: A meta-analytic review. Review of Educational Research, 70, 443-484.

Levine, S. C., Jordan, N. C., \& Huttenlocher, J. (1992). Development of calculation abilities in young children. Journal of Experimental Child Psychology, 53, 72-103.

Lipton, J., \& Spelke, E. (2006). Preschool children master the logic of number word meanings. Cognition, 98, B57B66. doi:10.1016/j.cognition.2004.09.013

Luria, A. R. (1973). The working brain: An introduction to neuropsychology. New York: Basic Books.

Matthews, J. S., Ponitz, C. C., \& Morrison, F. J. (2009). Early gender differences in self-regulation and academic achievement. Journal of Educational Psychology, 101, 689704. doi:10.1037/a0014240

Mazzocco, M. M. M., \& Kover, S. T. (2007). A longitudinal assessment of executive function skills and their association with math performance. Child Neuropsychology, 13, 18-45. doi:10.1080/09297040600611346

McGrew, K. S., \& Woodcock, R. W. (2001). Technical manual: Woodcock-Johnson III Tests of Achievement. Itasca, IL: Riverside.

Milner, B. (1963). Effects of different brain lesions on card sorting. Archives of Neurology, 9, 90-100.

Mix, K. S., Huttenlocher, J., \& Levine, S. C. (2002). Quantitative development in infancy and early childhood. New York: Oxford University Press.

Miyake, A., Friedman, N. P., Emerson, M. J., Witzki, A. H., \& Howerter, A. (2000). The unity and diversity of executive functions and their contributions to complex "frontal lobe" tasks: A latent variable analysis. Cognitive Psychology, 41, 49-100. doi:10.1006/cogp.1999.0734

Nieder, A., \& Dehaene, S. (2009). Representation of number in the brain. Annual Review of Neuroscience, 32, 185-208. doi:10.1146/annurev.neuro.051508.135550

Nieder, A., \& Miller, E. K. (2004). A parieto-frontal network for visual numerical information in the monkey. Proceedings of the National Academy of Sciences USA, 101, 7457-7462.

Noel, M.-P. (2009). Counting on working memory when learning to count and to add: A preschool study. Developmental Psychology, 45, 1630-1643. doi:10.1037/ a0016224

Pigott, T. D., \& Israel, M. S. (2005). Head Start children's transition to kindergarten: Evidence from the Early Childhood Longitudinal Study. Journal of Early Childhood Research, 3, 77-104. doi:10.1177/1476718X05051347

Ponitz, C. C., Rimm-Kaufman, S. E., Brock, L. L., \& Nathanson, L. (2009). Early adjustment, gender differences, and classroom organizational climate in first grade. Ele- mentary School Journal, 110, 142-162.

Resnick, L. B. (1989). Developing mathematical knowledge. American Psychologist, 44, 162-169.

Shalev, R. S. (1997). Neuropsychological aspects of developmental dyscalculia. Mathematical Cognition, 3, 105120.

Simpson, A., \& Riggs, K. J. (2006). Conditions under which children experience inhibitory difficulty with a "button press" go/no-go task. Journal of Experimental Child Psychology, 94, 18-26. doi:10.1016/j.jecp.2005.10.003

Spreen, O. (1988). Prognosis of learning disability. Journal of Consulting and Clinical Psychology, 56, 836-842.

St Clair-Thompson, H., \& Gathercole, S. E. (2006). Executive functions and achievements in school: Shifting, updating, inhibition and working memory. Quarterly Journal of Experimental Psychology, 59, 745-759. doi:10.1080/17470210500162854

Starkey, P. (1992). The early development of numerical reasoning. Cognition, 43, 93-126.

Vygotsky, L. S. (1978). Mind in society: The development of higher psychological processes. Cambridge, MA: Harvard University Press.

Welsh, M. C. (2002). Developmental and clinical variations in executive functions. In D. L. Molfese \& V. J. Molfese (eds.), Developmental variations in learning: Applications to social, executive Function, language and reading skills (pp. 139-187). Mahwah, NJ: Erlbaum.

Welsh, J. A., Nix, R. L., Blair, C., Bierman, K. L., \& Nelson, K. E. (2010). The development of cognitive skills and gains in academic school readiness for children from low-income families. Journal of Educational Psychology, 102, 43-53. doi:10.1037/a0016738

Wiebe, S. A., Espy, K., \& Charak, D. (2008). Using confirmatory factor analysis to understand executive control in preschool children: 1. Latent structure. Developmental Psychology, 44, 575-587. doi:10.1037/a0014550

Wiebe, S. A., Sheffield, T. D., Mize Nelson, J., Clark, C. A. C., Chevalier, N., \& Espy, K. A. (2011). Determining the structure of executive control in 3- year-old children: Further evidence for unity. Journal of Experimental Child Psychology, 108, 436-452. doi:10.1016/j.jecp.2010.08.008

Willoughby, M. T., Blair, C., Wirth, R. J., \& Greenberg, M. T. (2010). The measurement of executive function at age 3 years: Psychometric properties and criterion validity of a new battery of tasks. Psychological Assessment, 22, 306-317. doi:10.1016/j.jecp.2010.04.007

Woodcock, R. W., McGrew, K. S., \& Mather, N. (2001). Woodcock-Johnson III Tests of Achievement. Itasca, IL: Riverside.

Wynn, K. (1995). Infants possess a system of numerical knowledge. Current Directions in Psychological Science, 4, 172-177. 